\title{
Vibration analysis of simultaneous drilling and reaming BHA
}

\author{
Mohammed F. Al Dushaishi ${ }^{1}$ [D $\cdot$ Daniel S. Stutts ${ }^{2}$
}

Received: 31 January 2020 / Accepted: 5 August 2020 / Published online: 13 August 2020

(c) The Author(s) 2020

\begin{abstract}
The drillstring used in the oil and gas exploration is a complex structure due to the different forces acting on it. One of the primary sources of drillstring vibrations is the cutting forces caused by the drill bit contact with the rock formation. In some drilling applications, such as hole enlargement and underreaming, the source of the cutting action originates from the drill bit as well as the reamer which increases the dynamic complexity of the drillstring. This paper's objective is to investigate the torsional vibration behaviors of the bottom hole assembly (BHA) under simultaneous drilling and reaming. More specifically, it addresses the effect of the reamer interaction with the wellbore during drilling operations on the overall torsional vibrations of the BHA. The BHA was modeled as a torsional shaft subjected to a localized external force due to the reamer cutting action, and a point load external force due to the drill bit interaction with the formation. The equation of motion was obtained using Hamilton's principle, and modal expansion was used to solve the equation of motion. The results showed that the location of the reamer within the BHA plays an important role in vibrations response. It was found that vibration modes that exhibit symmetry within the reamer location show a negligible effect on the overall BHA torsional response. Reamers with aggressive cutters cause higher vibration response when compared with a drill bit with the same cutter aggressiveness. The simplified model reveals the significance of properly matching the drill bit and the reamer to reduce the overall BHA torsional vibrations.
\end{abstract}

Keywords Drillstring vibration $\cdot$ Stick-slip $\cdot$ Reaming while drilling $\cdot$ Modal analysis

\begin{tabular}{ll}
\multicolumn{2}{l}{ List of symbols } \\
$\delta$ & Dirac delta function \\
$\gamma$ & Damping coefficient \\
$\mu_{\mathrm{B}}$ & Bit aggressiveness \\
$\mu_{\mathrm{R}}$ & Reamer aggressiveness \\
$\omega$ & Forcing frequency \\
$\omega_{\mathrm{n}}$ & Natural frequency \\
$\rho$ & Linear mass density \\
$\theta$ & Torsional displacement \\
$\Theta_{\mathrm{s}}$ & Static response \\
$\tau(x, t)$ & External torque \\
$\left|\Theta_{d}(x, t)\right|$ & Total response \\
$D_{\mathrm{B}}$ & Bit diameter \\
$D_{\mathrm{i}}$ & BHA inside diameter
\end{tabular}

Mohammed F. Al Dushaishi m.aldushaishi@okstate.edu

Daniel S. Stutts stutts@mst.edu

1 Oklahoma State University, Stillwater, OK 74078, USA

2 Missouri University of Science and Technology, Rolla, MO 65409, USA
$D_{\text {o }} \quad$ BHA outside diameter

$G \quad$ Shear modulus

$H(x) \quad$ Heaviside step function

$I_{\mathrm{p}} \quad$ Polar moment of inertia

$L \quad$ BHA length

$n \quad$ Mode number integer

$s_{0} \quad$ Torque fluctuation constant

$t \quad$ Time

$T_{\mathrm{OB}}(x, t) \quad$ Torque on bit

$T_{\mathrm{OR}}(x, t) \quad$ Torque on reamer

$W_{\mathrm{OB}} \quad$ Weight on bit

$x_{2}-x_{1} \quad$ Reamer length

\section{Introduction}

One of the major challenges in drilling for oil and gas is drillstring vibrations. Drillstring vibrations could lead to premature failure of drilling components which leads to an increase in non-productive time. The drillstring consists of a series of drill pipes that connect and transmit torque to the bottom hole assembly (BHA). The BHA includes heavier 
drill pipes (i.e. drill collars, heavyweight drill pipes), stabilizers, the drill bit, and different instruments for measurement while drilling. Extending the borehole diameter beyond its original drilled size is a common practice in complex offshore drilling, where many casing strings are required to reach the target depth (Warren et al. 2017). Simultaneous drilling and reaming, or reaming while drilling (RWD), is achieved by drilling a pilot hole and enlarging the borehole to a target depth using concentric or eccentric underreamers. The underreamer is placed above the drill bit or the pilot hole and is activated either mechanically or hydraulically (Fig. 1).

During the drilling process, the drillstring is prone to axial, torsional, and lateral vibrations. Distinctive phenomena could occur with each vibration mode. For example, stick-slip vibration is one of the primary causes of destructive torsional vibration. Stick-slip vibration originates from the interaction of the drill bit and rock formations. In RWD, the interaction with the rock formation is due to the contact of the drill bit and the reamer because the reamer's blade diameter is larger than the drill bit or pilot hole diameter (Fig. 1).

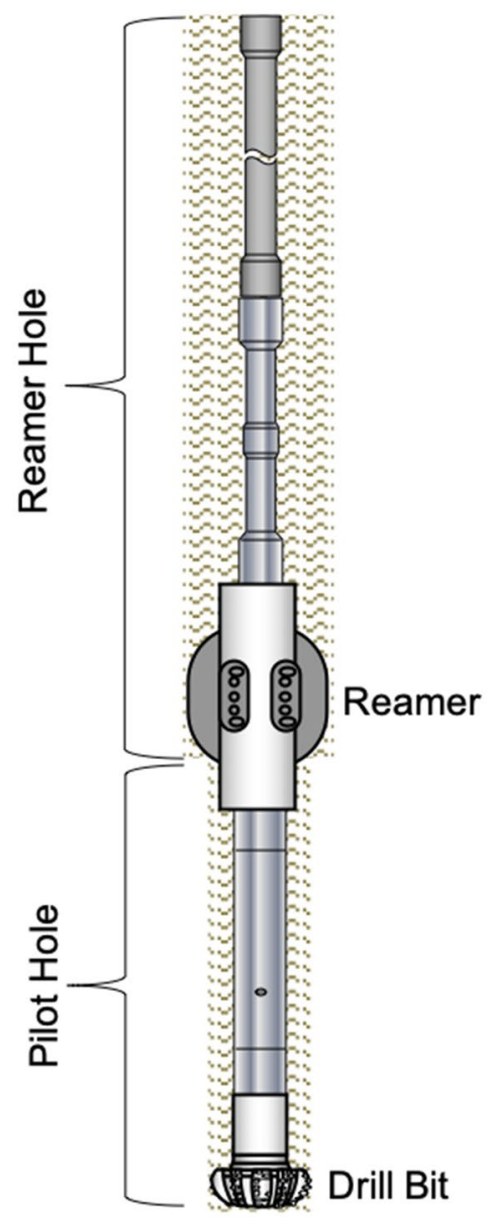

Fig. 1 Simultaneous drilling and reaming with pilot hole
Stick-slip vibrations occur during the contact with the rock formations. Numerous studies addressing stick-slip vibration were presented in several forms addressing the drill bit interaction with the rock formations (Challamel 2000; Leine et al. 2002; Ritto et al. 2009; Qiu et al. 2016). For instance, stickslip simulations were addressed through the coupled axialtorsional modes of the BHA via the interaction of the drill bit with the rock formation using finite element analysis (Qiu et al. 2016), an analytical approach such as the models by Challamel (2000), Richard et al. (2007), and a discrete system approach presented by Leine et al. (2002) and Yigit and Christoforou (2006). The dynamic stability of the drillstring under applied axial force and drillstring rotation were investigated to study the self-excited vibration of the drillstring due to bit interaction with rock formations by Challamel (2000) and Richard et al. (2007).

The effect of the contact forces between the rotating drillstring body and the wellbore wall was investigated in several studies where the forcing accounted for the drillstring center of mass eccentricity and the contact friction forces between the rotating drillstring and be borehole wall (Ritto et al. 2009; Jansen 1991).

This paper investigates the vibration behavior of the BHA during simultaneous drilling and reaming in vertical wells. The BHA was modeled as a torsional shaft subjected to a force at the bit and a localized stick-slip force acting across the BHA, where the underreamer is placed to enlarge the pilot hole. The equation of motion was obtained using Hamilton's principle, and modal expansion was used to solve the equation of motion.

\section{Problem statement}

The drillstring is simplified; only the torsional mode of the BHA is considered. More realistic models take into account the shear forces, prestress, and coupling effects (Al Dushaishi et al. 2017). The objective of this paper is to show the effect of concentrated torque due to the underreamer interaction in RWD operations, and thus a simplified uncoupled model is used. The BHA was modeled as a fixed-free torsional shaft under torsional excitation due to the interaction of the drill bit and the underreamer with the rock formation (Fig. 2).

The uncoupled torsional equation of motion of the BHA is obtained using the Hamilton's principle following Al Dushaishi et al. (2017).

$\rho I_{\mathrm{p}} \frac{\partial^{2} \theta}{\partial t^{2}}+\gamma \frac{\partial \theta}{\partial t}-I_{\mathrm{p}} G \frac{\partial^{2} \theta}{\partial x^{2}}=\tau(x, t)$

where $\rho$ is the linear mass density, $I_{\mathrm{p}}$ is the polar moment of inertia, $\gamma$ is the damping coefficient, $G$ is the shear modulus, $\theta$ is the torsional displacement, and $\tau(x, t)$ is the external torque. 


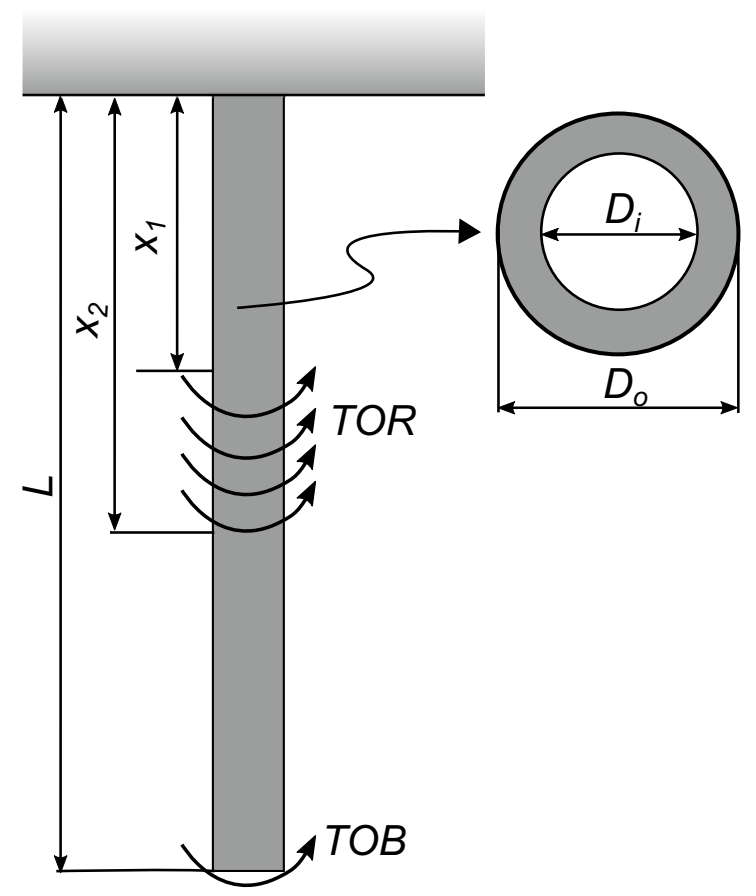

Fig. 2 Modeling schematics

The external torque includes torsional excitations due to the drill bit and the reamer interaction with the rock as:

$\tau(x, t)=T_{\mathrm{OB}}(x, t)+T_{\mathrm{OR}}(x, t)$

where $T_{\mathrm{OB}}$ and $T_{\mathrm{OR}}$ represent the torque on bit and torque on reamer, respectively.

The torque on bit is assumed to be harmonic following:

$T_{\mathrm{OB}}(x, t)=\tau_{\mathrm{B}}\left(1+s_{0} \sin (\omega t)\right) \delta(x-l)$

where $\delta(x)$ is the Dirac delta function, $\omega$ is the forcing frequency, $s_{0}$ is the torque fluctuation constant that is a function of bit rock interaction, and $\tau_{\mathrm{B}}$ is defined as:

$\tau_{\mathrm{B}}=\mu_{\mathrm{B}} \alpha_{\mathrm{B}} W_{\mathrm{OB}}$

where $W_{\mathrm{OB}}$ represents the applied axial load (weight on bit), $\mu_{\mathrm{B}}$ is the aggressiveness of the cutters defined by Coulomb friction ratio, and $\alpha_{\mathrm{B}}$ is the bit specific mean leaver defined as a function of the bit diameter $D_{\mathrm{B}}$ as defined by Kueck et al. (2017) as:

$\alpha_{\mathrm{B}}=\frac{1}{4} D_{\mathrm{B}}$

The reamer is assumed to be concentric and engaged. In this case, the torque on the reamer per unit length can be modeled as a localized harmonic torsional excitation described by:
$T_{\mathrm{OR}}(x, t)=\tau_{\mathrm{R}}\left(1+s_{0} \sin (\omega t)\right)\left[H\left(x-x_{1}\right)-H\left(x-x_{2}\right)\right]$

where $H(x)$ denotes the Heaviside step function; $x_{2}-x_{1}$ is the length of the reamer, and $\tau_{\mathrm{R}}$ is defined the same way as $\tau_{\mathrm{B}}$ where the reamer specific mean lever is (Kueck et al. 2017):

$\alpha_{\mathrm{R}}=\frac{1}{4}\left(D_{\mathrm{R}}+D_{\mathrm{B}}\right)$

Applying separation of variables followed by applying the boundary conditions to the homogenous part of the equation of motion (Eq. (1)), the $n$th natural frequency and mode shape are given by:

$\omega_{\mathrm{n}}=\frac{(2 n-1) \pi}{2 L} \sqrt{\frac{G}{\rho}}$

$\Theta_{n}(x)=\sin \left(\frac{(2 n-1) \pi}{2 L} x\right)$

The steady state response, using the modal analysis, has the following solution form:

$\theta(x, t)=\sum_{n=1}^{\infty} \eta_{n}(t) \Theta_{n}(x)$

where $\Theta_{n}(x)$ is the $n$th normalized mode shape given by Eq. (9), and $\eta_{n}(t)$ is the $n$th generalized coordinate. Substituting Eqs. (9) and (10) into Eq. (1) and establishing modes orthogonality, following Soedel (2004), yields

$\ddot{\eta}_{n}+2 \zeta_{n} \omega_{\mathrm{n}} \dot{\eta}_{n}+\omega_{\mathrm{n}}^{2} \eta_{n}=F_{n}(x, t)$

where $2 \zeta_{n} \omega_{n}=\gamma / \rho I_{P}$, and

$F_{n}(x, t)=\frac{2}{\rho I_{\mathrm{p}} L} \int_{0}^{L} \tau(x, t) \sin \left(\frac{(2 n-1) \pi}{2 L} x\right) d x$

Substituting Eq. (2) in the modal forcing function, Eq. (12), yields

$F_{n}(x, t)=\left(Q_{\mathrm{B}}+Q_{\mathrm{R}}\right)(1+\sin (\omega t))$

where

$Q_{\mathrm{B}}=\frac{(-1)^{n-1} \tau_{\mathrm{B}}}{\rho I_{\mathrm{p}} L}$

and

$$
\begin{aligned}
Q_{\mathrm{R}}= & \frac{4 \tau_{\mathrm{R}}}{\rho I_{\mathrm{p}}(2 n-1) \pi}\left[\cos \left(\frac{(2 n-1) \pi}{2 L} x_{1}\right)\right. \\
& \left.-\cos \left(\frac{(2 n-1) \pi}{2 L} x_{2}\right)\right]
\end{aligned}
$$


The total steady state response of the BHA, assuming zero initial conditions, is

$\theta(x, t)=\sum_{n=1}^{\infty}\left(\eta_{n s}(x)+\eta_{n}(t)\right) \sin \left(\frac{(2 n-1) \pi}{2 L} x\right)$

where $\eta_{n s}(x)$ and $\eta_{n}(t)$ are, respectively, the static and dynamic responses written as:

$\eta_{n s}(x)=\frac{Q_{\mathrm{B}}+Q_{\mathrm{R}}}{\omega_{n}^{2}}$

$\eta_{n}(t)=\left|\Lambda_{n}(\omega)\right| \sin (\omega t-\Phi)$

where

$\left|\Lambda_{n}(\omega)\right|=\frac{Q_{\mathrm{B}}+Q_{\mathrm{R}}}{\sqrt{\left(\omega_{n}^{2}-\omega^{2}\right)+4 \zeta_{n}^{2} \omega_{n}^{2} \omega^{2}}}$

and

$\Phi= \begin{cases}\tan ^{-1}\left(\frac{2 \zeta_{n} \omega_{n} \omega}{\omega_{n}^{2}-\omega^{2}}\right), & \omega \leq \omega_{n} \\ \pi-\tan ^{-1}\left(\frac{2 \zeta_{n} \omega_{n} \omega}{\omega_{n}^{2}-\omega^{2}}\right), & \omega>\omega_{n}\end{cases}$

The frequency response function (FRF) is obtained by separating the magnitude and phase of the total response in Eq. (16). Using trigonometric identities and the phasor representation, the maximum steady state response magnitude is

$|\theta(x, t)|_{\max }=\sum_{n=1}^{\infty} \Theta_{n s}(x)+\left|\Theta_{d}(x, t)\right|$

where

$\Theta_{n s}(x)=\eta_{n s}(x) \sin \left(\frac{(2 n-1) \pi}{2 L} x\right)$

and

$$
\begin{aligned}
\left|\Theta_{d}(x, t)\right|=\left\{\left(\sum_{n=1}^{\infty} \Theta_{\mathrm{n}}(x) \Lambda_{n}(\omega) \cos \left(\phi_{n}\right)\right)^{2}\right. \\
\left.+\left(\sum_{n=1}^{\infty} \Theta_{\mathrm{n}}(x) \Lambda_{n}(\omega) \sin \left(\phi_{n}\right)\right)^{2}\right\}
\end{aligned}
$$

\section{System response}

A BHA from a field study of a vertical well using reaming while drilling BHA (Kueck et al. 2017) was used in this analysis. Slight modification was applied to the total length of the BHA used in the field study for simplicity, Table 1 shows the parameters used in the analysis. The location of the excitation torque of the reamer $\left(x_{2}-x_{1}\right)$ was assumed to occur within the entire reamer joint (stand). The torque fluctuation constant $s_{0}$ was assumed to be 0.25 for the reamer and the bit.

From free vibration analysis (Eqs. (8-9)), the first six normalized modes are shown in Fig. 3, where the solid black lines represent the location of the localized torque due to the reamer stick-slip force. It can be observed that as the mode number increases, the number of nodes with zero displacement increases. Examining each mode shape shows that the location of the zero displacement node is located in the middle of the localized reamer force for the 6th mode. The first three natural frequencies of the BHA are 49.643, 148.93, and $248.22 \mathrm{rad} / \mathrm{s}$.

\section{BHA response due to simultaneous drilling and reaming}

The torsional response due to the static component of the stickslip torque is shown in Fig. 4, which shows the response when considering the static torque applied at the bit, the reamer, and the combined bit and reamer. As expected, considering only the force at the bit has the lowest response, while the highest response is seen with the combined forces (Fig. 4).

Considering the damping components such as fluid damping, a 10spsper damping ratio for the first mode was assumed, and the damping constant, $\gamma$, back-calculated. The damping ratio $\zeta$ was obtained as

$\gamma=0.1 \times 2 \rho I_{\mathrm{p}} \omega_{1}$

$\zeta_{n}=\frac{\gamma}{2 I_{\mathrm{p}} \rho \omega_{n}}$

Figure 5 shows the magnitude frequency response at $x=L$ due to the bit torque, the reamer torque, and the combined bit and reamer torques. The static force component of the

Table 1 Input data

\begin{tabular}{llll}
\hline Parameter & Value & Parameter & Value \\
\hline$L$ & $100 \mathrm{~m}$ & $D_{\mathrm{B}}$ & $0.1524 \mathrm{~m}$ \\
$D_{\mathrm{o}}$ & $0.121 \mathrm{~m}$ & $D_{\mathrm{R}}$ & $0.222 \mathrm{~m}$ \\
$D_{\mathrm{i}}$ & $0.0571 \mathrm{~m}$ & $\mu_{\mathrm{B}}$ & 0.5 \\
$\rho$ & $7800 \mathrm{~kg} \mathrm{~m}^{-3}$ & $\mu_{\mathrm{R}}$ & 0.5 \\
$G$ & $77.9 \times 10^{9} \mathrm{~Pa}$ & $x_{1}$ & $70 \mathrm{~m}$ \\
$W O B$ & $100 \mathrm{KN}$ & $x_{2}$ & $76 \mathrm{~m}$ \\
\hline
\end{tabular}




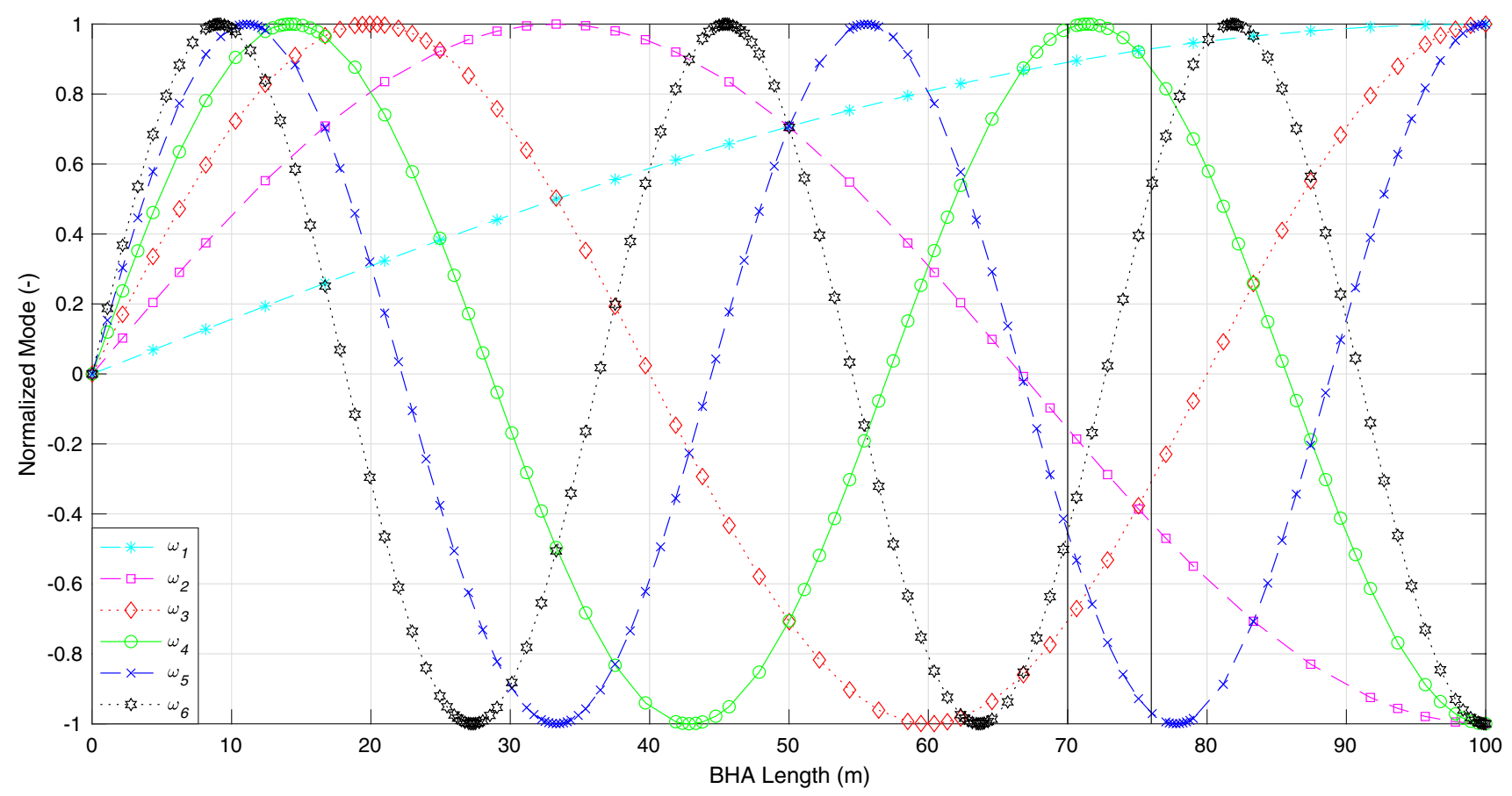

Fig. 3 First six mode shapes

Fig. 4 Torsional response due to the static torque applied at the bit, the reamer, and the combined bit and reamer

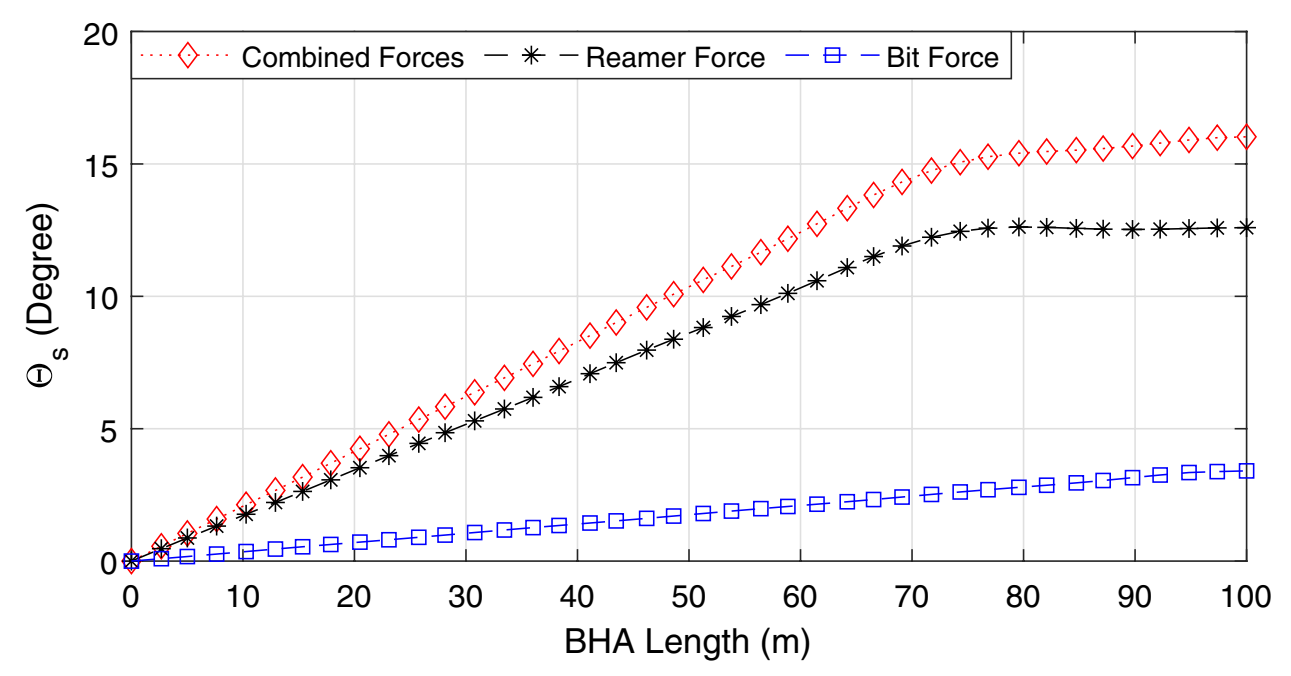

stick-slip force only contributes to the DC part of the frequency spectrum as seen in Fig. 5 at zero Hertz. The frequency responses due to the combined torques and the reamer torque have similar magnitude, while the frequency response magnitude of the drill bit torque is the lowest. Interestingly, the excitation frequency of the 6th mode $\left(f_{6}=86.9 \mathrm{~Hz}\right)$ for the localized torque cases (reamer torque and combined torques) vanishes from the frequency spectrum as seen in Fig. 5. This behavior can be explained by examining the mode shape in Fig. 3. Due to the fact that the zero displacement node of the 6th mode is located exactly at the center of the forcing function location and exhibits symmetry, the 6th mode is not excited.

To better illustrate the nature of the frequency response spectrum and reveal which excitation frequencies vanish, analysis of the phase angle is required. Figure 6 shows the phase frequency response due to the bit and reamer torque, and their combination. At each excitation frequency, a phase shift can be noticed for all the three cases (Fig. 6). For the 6 th mode $\left(f_{6}\right)$, however, the phase shift can only be seen in the drill bit torque case. The 6 th mode does not exhibit a phase shift for the reamer torque, and only a small phase 
Fig. 5 Frequency response magnitude due to torque at the bit, torque at the reamer, and combined torques of the bit and the reamer

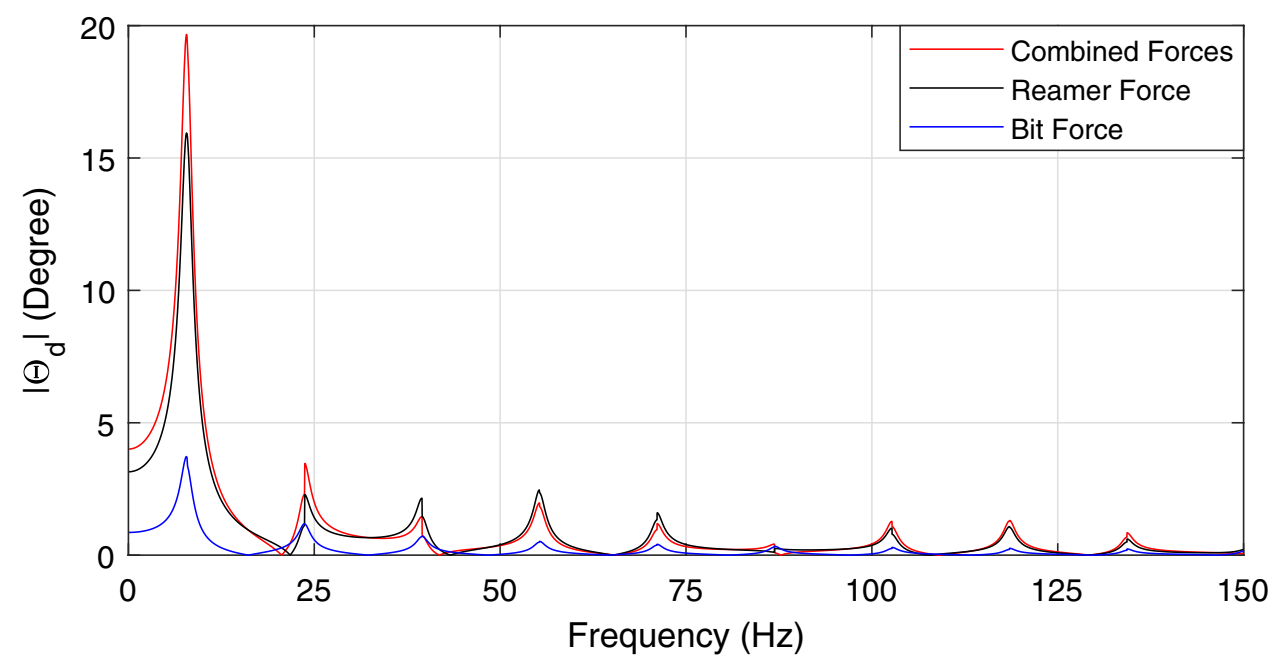

shift for the combined torques; thus it does not contribute to the overall BHA response as seen in the frequency response spectrum (Fig. 6).

\section{Sensitivity analysis}

Sensitivity analysis is highlighted in this section to show the effect of placing the reamer in a different location across the BHA length as well as changes in cutter aggressiveness, $\mu_{\mathrm{B}}$, for both the bit and the reamer, and changes in the reamer outside diameter.

The magnitude of the vibration response and the phase frequency response is shown in Figs. 7 and 8, respectively, when the reamer is placed at a different location across the BHA length. Placing the reamer at $x_{1}=90 \mathrm{~m}$ shows the highest magnitude in the first four excitation frequencies. At the first excitation frequency, the lowest response is seen when placing the reamer at $x_{1}=30 \mathrm{~m}$. At approximately $\left(f_{9}=134.3 \mathrm{~Hz}\right)$, the reamer placed at $x_{1}=90$ $\mathrm{m}$ has no contribution, i.e. zero response, which can also be noticed in the phase frequency response in Fig. 8.

Using the base case (Table 1), the effect of cutter aggressiveness for both the drill bit and the reamer on the BHA vibration response was investigated. Figures 9 and 10 show, respectively, the magnitude and phase frequency response of the BHA for a combination of different cutter aggressiveness parameter values. Overall, a more aggressive reamer results in higher vibration magnitude when compared to the same bit aggressiveness.

The same base case was used to investigate the effect of changing the reamer size while maintaining the size of the drill bit. The BHA vibration response was computed for varying reamer sizes, where the magnitude frequency response is shown in Fig. 11. The frequency response shows that increasing the reamer size from $0.17 \mathrm{~m}(63 / 4$
Fig. 6 Phase frequency response due to torque at the bit, torque at the reamer, and combined torques of the bit and the reamer

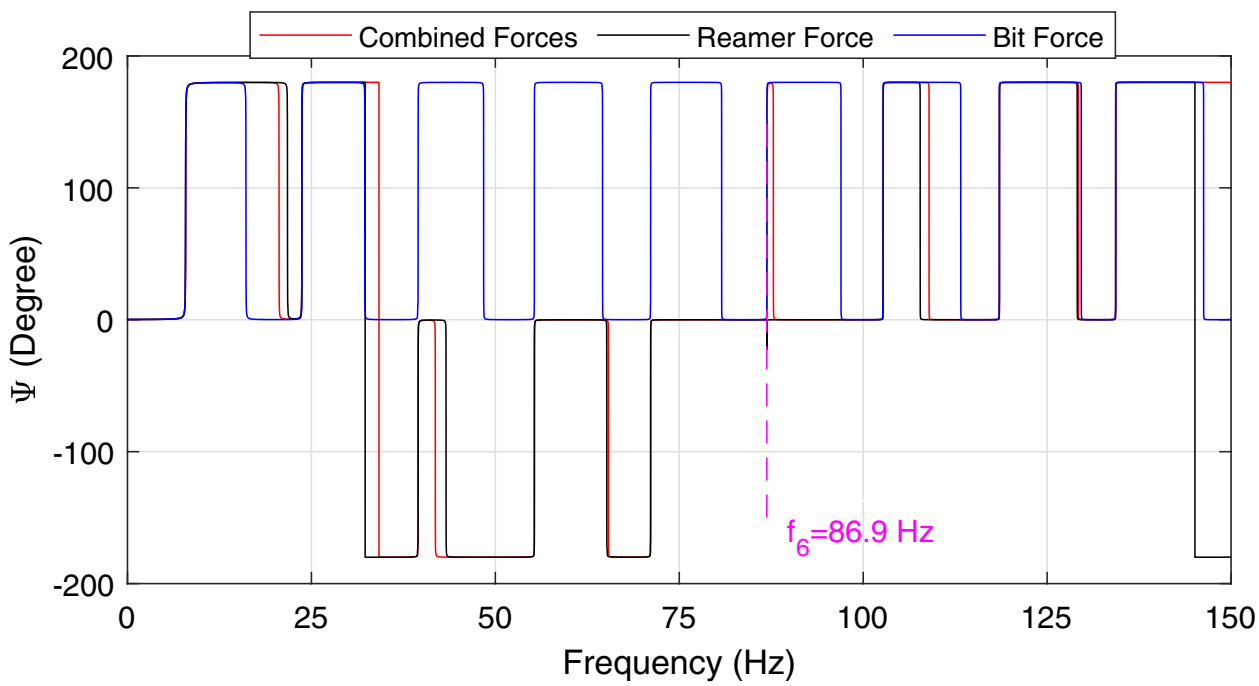


Fig. 7 Frequency response magnitude for different reamer locations
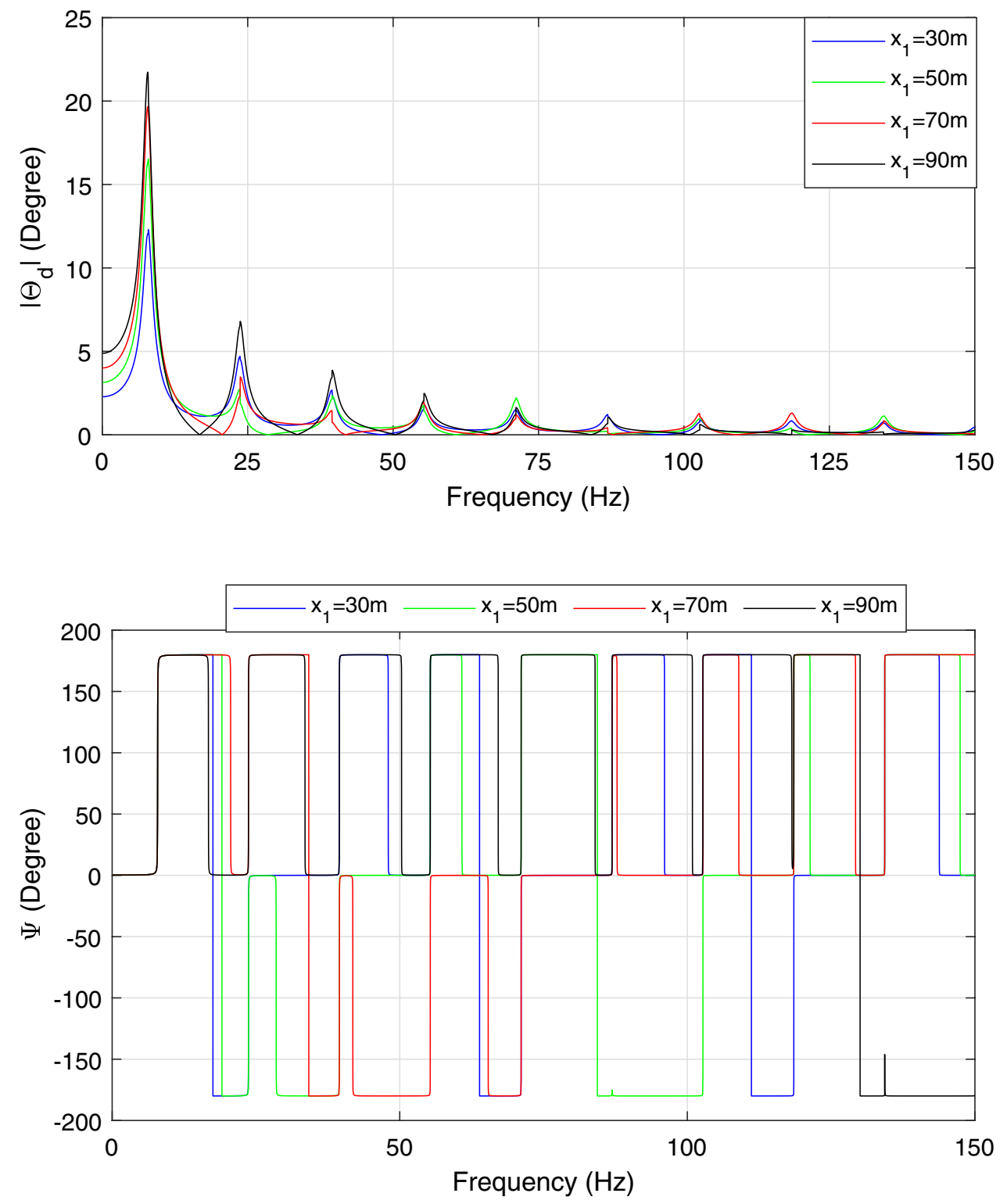

Fig. 8 Phase frequency response magnitude for different reamer locations adequately describe the dynamics due to the concentrated torque in simultaneous drilling and reaming.

Reamer location and length affect the modes that contribute to the overall BHA torsional response. Modes that exhibit symmetry within the length of the reamer show negligible torsional response (Figs. 5 and 6). From an optimization point of view, the reamer could be placed in an optimum location where the modes will exhibit symmetry to decrease the torsional excitation of certain modes. This methodology can be used to optimize the reamer placement for a given driving frequency, i.e. rotational speed.

Sensitivity analysis showed that a more aggressive bit accompanied by a less aggressive reamer yield a lower torsional response (Figs. 9 and 10). Generally, less aggressive cutters for both the drill bit and the reamer will result
Previous studies (Ritto et al. 2009; Jansen 1991) addressing drillstring contacts with the wellbore wall do not
Including a localized force within the BHA has a significant effect on the torsional response (Fig. 3). In reaming while drilling or underreaming operations, the resultant 
Fig. 9 Frequency response magnitude for different cutters aggressiveness

Fig. 10 Phase frequency response magnitude for different cutters aggressiveness

Fig. 11 Frequency response magnitude for varying reamer sizes
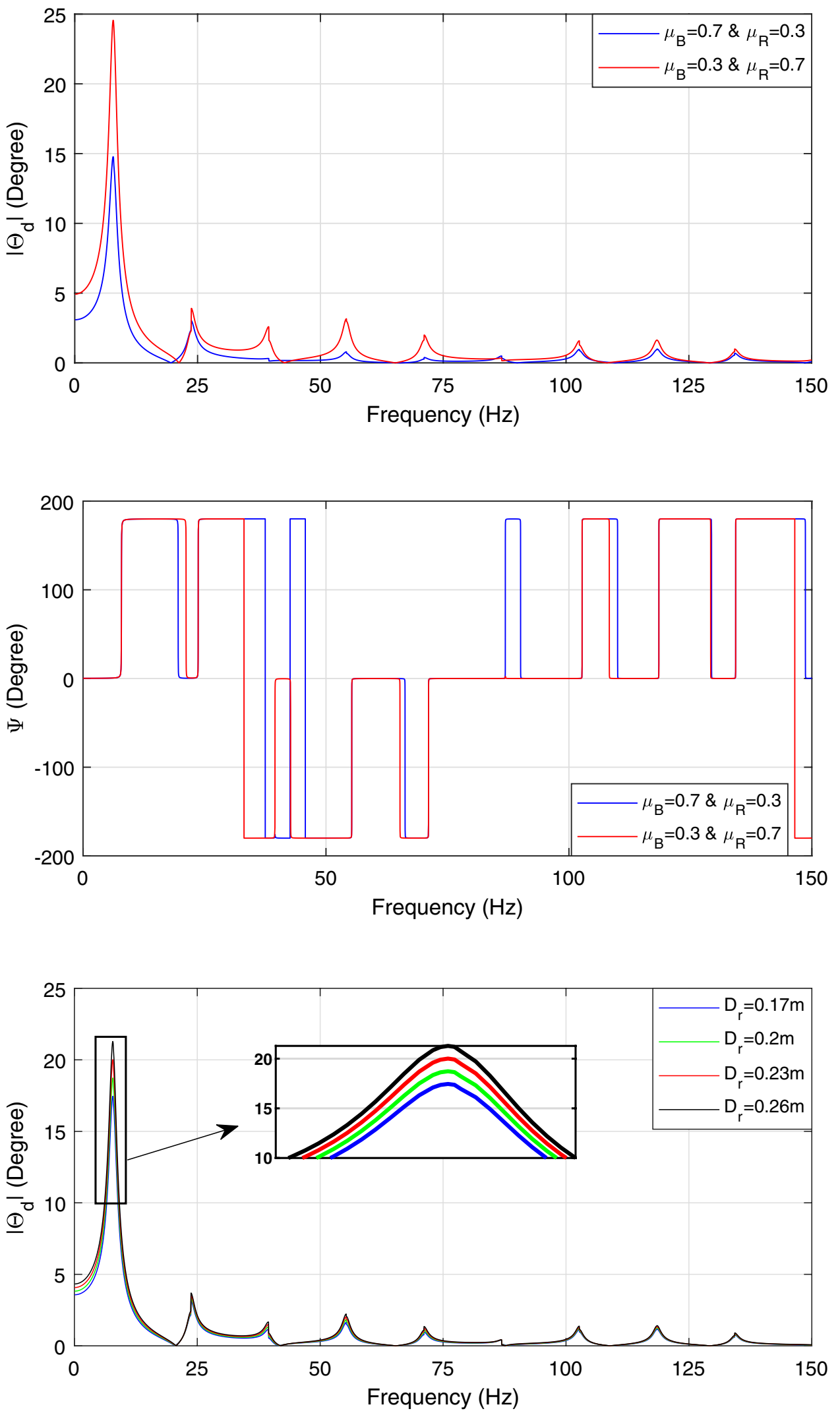
in less vibration magnitude; however, this will limit the rate of penetration.

The analysis of changing the reamer size from $0.17 \mathrm{~m}(6$ $3 / 4$ inches) to $0.26 \mathrm{~m}$ (10 15/64 inches) showed an insignificant increase, i.e. 3 degrees increase at $21 \mathrm{~Hz}$, in the BHA frequency response (Fig. 11). Further, a slight increase in the magnitude response was noticed due to the static response, i.e. at zero frequency. With the conditions used in this paper, increasing the reamer size by $90 \mathrm{~mm}$ (3 1/2 inches) showed insignificant change in the BHA frequency response. The study did not consider reamers larger than $0.26 \mathrm{~m}$ in diameter because this was the largest reamer size available for the selected bit size. As a result, for larger reamers that are compatible with larger bits, the BHA response will differ.

The model presented here mimics a realistic BHA in a simplified manner, and hence, further model features are required to describe the full dynamic behavior due to the reamer's interaction with the rock formation and to better represent the complex geometry of the BHA. Nevertheless, this simplified model can be used as a guide for selecting reamer aggressiveness, size, and placement within a BHA.

\section{Conclusions}

In this paper, a simplified analytical model addressing the effect of localized external torque due to reamer interaction with the formation in simultaneous drilling and reaming application is presented. The equation of motion was obtained using Hamilton's principle, and modal expansion was used to solve the equation of motion. The study showed:

- The localized external torque caused by reamer interaction during simultaneous drilling and reaming has a significant influence on the overall BHA torsional response.

- The location of the reamer within the BHA plays an important role in vibration response. Vibration modes that exhibit symmetry within the reamer showed a negligible effect in the torsional response.

- Aggressive reamer cutters will cause a higher vibration response. The results showed that a bit with aggressive cutters should be accompanied by a less aggressive reamer.

- Under the conditions used in this paper, increasing the reamer size for up to $0.26 \mathrm{~m}$ (10 15/64 inches) with a drill bit of $0.17 \mathrm{~m}$ (6 3/4 inches) showed an insignificant increase of only 3 degrees at $21 \mathrm{~Hz}$ in the BHA frequency response.
Open Access This article is licensed under a Creative Commons Attribution 4.0 International License, which permits use, sharing, adaptation, distribution and reproduction in any medium or format, as long as you give appropriate credit to the original author(s) and the source, provide a link to the Creative Commons licence, and indicate if changes were made. The images or other third party material in this article are included in the article's Creative Commons licence, unless indicated otherwise in a credit line to the material. If material is not included in the article's Creative Commons licence and your intended use is not permitted by statutory regulation or exceeds the permitted use, you will need to obtain permission directly from the copyright holder. To view a copy of this licence, visit http://creativecommons.org/licenses/by/4.0/.

\section{References}

Al Dushaishi MF, Nygaard R, Stutts DS (2017) An analysis of common drill stem vibration models. J Energy Resour Technol 140(1):012905

Challamel N (2000) Rock destruction effect on the stability of a drilling structure. J Sound Vib 233(2):235-254. https://doi.org/10.1006/ jsvi.1999.2811

Jansen JD (1991) Non-linear rotor dynamics as applied to oilwell drillstring vibrations. J Sound Vib 147(1):115-135. https://doi. org/10.1016/0022-460X(91)90687-F

Kueck A, Ichaoui M, Herbig C, Hohl A, Ostermeyer GP, Reckmann H (2017) Optimal matching of bit and reamer for increased reliability of hole-opening bhas. Presented at the Abu Dhabi international petroleum exhibition \& conference, 13-16 November, Abu Dhabi, UAE SPE-105400-MS, https://doi.org/10.2118/188709-MS

Leine RI, van Campen DH, Keultjes WJG (2002) Stick-slip whirl interaction in drillstring dynamics. J Vib Acoust 124(2):209-220. https ://doi.org/10.1115/1.1452745

Qiu H, Yang J, Butt S (2016) Stick-slip analysis of a drill string subjected to deterministic excitation and stochastic excitation. Shock Vib. https://doi.org/10.1155/2016/9168747

Richard T, Germay C, Detournay E (2007) A simplified model to explore the root cause of stick-slip vibrations in drilling systems with drag bits. J Sound Vib 305(3):432-456. https://doi. org/10.1016/j.jsv.2007.04.015

Ritto T, Soize C, Sampaio R (2009) Non-linear dynamics of a drillstring with uncertain model of the bit-rock interaction. Int J NonLinear Mech 44(8):865-876. https://doi.org/10.1016/j.ijnonlinme c. 2009.06.003

Soedel W (2004) Vibrations of shells and plates, 3rd edn. Marcel Dekker, Inc, New York

Warren TM, Sinor LA, Dykstra MW (2017) Simultaneous drilling and reaming with fixed blade reamers. Presented at the SPE annual technical conference and exhibition, 22-25 October, Dallas, Texas SPE-30474-MS, https://doi.org/10.2118/30474-MS

Yigit AS, Christoforou AP (2006) Stick-slip and bit-bounce interaction in oil-well drillstrings. J Energy Resour Technol 128(4):268-274. https://doi.org/10.1115/1.2358141

Publisher's Note Springer Nature remains neutral with regard to jurisdictional claims in published maps and institutional affiliations. 